\title{
AS IMPLICAÇÓES DA BOA-FÉ COMO REGRA COGENTE NOS NEGÓCIOS INTERNACIONAIS À LUZ DA CONVENÇÃO DE VIENA SOBRE COMPRA E VENDA INTERNACIONAL DE MERCADORIAS DE 1980
}

\author{
THE IMPLICATIONS OF GOOD FAITH AS A COGENT \\ RULE IN INTERNATIONAL BUSINESS UNDER THE \\ UNITED NATIONS CONVENTION ON CONTRACTS \\ FOR THE INTERNATIONAL SALE OF GOODS OF 1980
}

\author{
RENATA ALVARES GASPAR ${ }^{1}$ \\ MARIANA ROMANELLO JACOB ${ }^{2}$
}

\section{RESUMO}

Este artigo teve por objeto a análise da boa-fé objetiva nos negócios internacionais à luz da Convenção das Nações Unidas sobre Contratos de Compra e Venda Internacional de Mercadorias de 1980 (CISG, sigla em inglês). Para realizar tal análise, o estudo partiu, primeiramente, da premissa de que a boa-fé da era globalizada sofreu e vem sofrendo transmutações como resposta do Direito às mudanças que o comércio internacional impõe, pesquisando suas possíveis razões. Aclaradas as motivações de tais mudanças, focou-se na atual configuração da boa-fé no comércio globalizado, desenhando-se os alcances e limites do instituto nas relações multiconectadas, reunidoras de sistemas jurídicos distintos e, às vezes, quase

1 Pós-Doutoranda do PPGD da Universidade Federal de Uberlândia, com Bolsa CNPq. Doutora em Direito pela Universidade de Salamanca-España (2008) e mestre em Estudios Latinoamericanos (menção Ciências Políticas/Direitos Humanos) pela mesma Universidade (2005). Ambos os títulos revalidados pela USP - Universidade de São Paulo. Consultora Jurídica para do MERCOSUL no Projeto Focem Base de dados Jurisprudencial (2008). Vice-Presidenta de Comunicação e Publicações da ASADIP - Associação Americana de Professores de Direito Internacional (2017-2019). Pesquisadora integrante da Rede de Pesquisa de Processo Civil Internacional (UFU, Coordenador Professor Dr. Thiago Paluma). Autora de livros e artigos científicos. Desenvolve projetos de pesquisa no âmbito do Direito Processual Civil Internacional. Líder do Grupo de Estudo Direito, Globalização e Cidadania. Membro da Academia Brasileira de Direito Internacional. Consultora jurídica atuante na área de Direito Internacional Privado e Cooperação Jurídica Internacional. ORCID iD: http://orcid.org/0000-0002-2600-3686. E-mail: renataalvaresgaspar@gmail.com.

2 Graduada em Direito pela Pontifícia Universidade Católica de Campinas. Membro do Grupo de Estudos "Direito, Globalização e Cidadania" sob Liderança da Prof ${ }^{a}$. Dr ${ }^{a}$. Renata Alvares Gaspar. Membro da Associação Americana de Direito Internacional Privado (ASADIP). Advogada. E-mail: mariana.romanello@gmail.com. 
opostos; para tanto a CISG foi essencial, pois é instrumento emblemático de vocação uniformizadora do direito contratual internacional, cuja estruturação enseja uma flexibilização relevante aos diversos sistemas que a manuseiam. Para os fins do presente estudo, adotou-se, portanto, o método indutivo, eis que se parte de um recorte determinado, qual seja, a boa-fé à luz da CISG, para compreensão dos impactos que esta nova configuração da boa-fé gerou - e vem gerando - nos negócios transnacionais de forma geral. A título de conclusão foca-se nessa compreensão e, em especial, ao que se exige dos contratantes à luz dessa repaginação. No que toca ao procedimento, fez-se uso pesquisa bibliográfica, majoritariamente doutrinária, porém com alguns contributos da normatização e diálogo de fontes internacionais, bem como da jurisprudência, sobretudo para corroborar a indução ora adotada como método.

Palavras-chave: Boa-fé objetiva. Direito do comércio internacional. Negócios jurídicos internacionais. CISG.

\section{ABSTRACT}

This article had as object the analysis of the duty of good faith in international business in the light of United Nations Convention on Contracts for the International Sale of Goods of 1980 (CISG). To carry out such analysis the study started from the premise that the duty of good faith of the globalized era has suffered and has undergone transmutations as a response from Law to the changes that international trade imposes, researching its possible reasons. Once clarified the motivations for such changes, this study focused on the present configuration of good faith in globalized commerce, drawing the scope and limits of the institute in the multiconnected relations, which bring together distinct and sometimes almost opposite legal systems; to this end, the CISG was essential, as it is an emblematic instrument with a unifying vocation of international contractual law, whose structure provides a relevant flexibility to the various systems that handle it. Therefore, for the purposes of this study the inductive method was adopted, since is based on a specific clipping, that is, good faith in light of CISG, to comprehend the impacts that this new configuration of good faith has generated - and is generating - in transnational businesses, especially those required of contractors under light of this revamp. Regarding to procedure, it was used bibliographic research, mostly doctrinal, but also with some contributions from the normatization and dialogue of international sources, as well as from the jurisprudence, mainly to corroborate the induction adopted as method.

Keywords: Duty of good Faith. Trade international law. International legal business. CISG.

\section{INTRODUÇÃO}

Verdadeira expressão objetiva da conduta humana, como forma de exteriorização da ética e padronização de condutas consideradas leais ${ }^{3}$, a boa-fé objetiva acompanha o comércio muito antes deste se esbarrar nas fronteiras dos estados nacionais e, posteriormente, dissociar-se delas com o movimento de globalização.

Afinal, já nos tempos do medievo germânico ${ }^{4}$, a feição objetiva da boa-fé começou a tomar corpo pelo agir na toada do treu und glauben, desviando-se, pouco a pouco, da esfera subjetiva e reajustando o foco para a conduta exteriorizada, independentemente de elementos íntimos do sujeito.

3 Sob a perspectiva de intepretação oriunda do direito alemão e da conotação atribuída nos países da common law, Judith Martins-Costa (MARTINS-COSTA, 1995, p. 120), citando Ernesto Wayar (WAYAR, Tomo I, p. 19), descreve uma composição de elementos do que significa, de forma geral, a boa-fé objetiva: "(...) se quer significar (...) modelo de conduta social, arquétipo ou standard jurídico - segundo o qual 'cada pessoa deve ajustar a sua própria conduta a esse arquétipo, obrando como obraria um homem reto: com honestidade, lealdade, probidade"'.

4 António Menezes Cordeiro (MENEZES CORDEIRO, 2011, p. 162-176) ensina que os juramentos de honra durante o medievo germânico são um marco para a acepção objetiva da boa-fé. 
Ocorre que, multifacetada por definição - eis que reflete, na essência, comportamento humano - e instrumento jurídico cada vez mais reconhecido como apto a conferir segurança nas relações comerciais, a boa-fé objetiva, com o passar do tempo, veio sendo redimensionada em relevância e, por consequência, em imperatividade. E as vicissitudes e idiossincrasias da globalização foram, em especial, um contexto potencializador dessa mutação.

Isso porque, a disseminação acentuada e acelerada do comércio em escala global, a virtualização das relações comerciais, os consequentes encontros - e choques - de pluralidades próprios do comércio além-fronteiras e as vultosas transações econômicas que decorreram dessas novas possibilidades - somadas, às crises econômicas provocadas no todo desse conjunto - conformam o cenário onde a acepção objetiva da boa-fé ganhou uma dimensão ainda não experimentada até então: a boa-fé adquire, nesse contexto, locus para remodelar-se de princípio jurídico à regra cogente; noutras palavras, deixa de apenas “iluminar" o caminho e se torna o próprio caminho - ao menos, o autenticamente legítimo.

A Convenção de Viena sobre Compra e Venda Internacional de Mercadorias de 1980 (CISG, na sigla em inglês), é expressão emblemática dessa mutação, porque consagra a boa-fé objetiva em seu artigo $7^{\circ}$ de forma expressa e inequívoca: "(1) Na interpretação desta Convenção ter-se-ão em conta seu caráter internacional e a necessidade de promover a uniformidade de sua aplicação, bem como de assegurar o respeito à boa fé no comércio internacional." 5 .

Ao fazê-lo, sendo instrumento clássico de hard law, posiciona a boa-fé em status de cogência e, portanto, obrigatoriedade de observância. Isso provoca uma ressignificação do papel da boa-fé nos negócios jurídicos: sob a égide dessa Convenção, a boa-fé é norma de cumprimento obrigatório; e, nessa qualidade, um importante limitador à autonomia de vontades.

Tamanhas, aliás, foram as dimensões que a boa-fé objetiva ganhou no contratar contemporâneo que, para além do campo do hard law - onde a cogência é o elemento de definição - até mesmo instrumentos do soft law ${ }^{6}$, tão preciosos à dinamicidade do comércio transfronteiriço e tão manuseáveis em nome da autonomia da vontade, foram impactados por essa imperatividade a ponto de lhes ser vedado unicamente o afastamento da cláusula de boa-fé.

Os Princípios UNIDROIT, por exemplo, clássico instrumento do soft law, embora consagrem já em seu primeiro artigo a liberdade de contratação e a autonomia da vontade, preveem, no artigo 1.7, o dever de boa-fé objetiva como obrigação inafastável ou sequer manuseável aos contratantes: "(1) Cada parte deve agir de acordo com a boa-fé e a negociação justa no comércio internacional. (2) As partes não podem excluir ou limitar esta obrigação." (Grifo nosso. Tradução nossa do original em inglês) ${ }^{7}$

50 teor deste artigo e de outros dispositivos da CISG ao longo deste texto são transcritos do Decreto Presidencial, ${ }^{\circ}$ 8.327/2014, que internalizou a convenção ao ordenamento brasileiro. Considerando que a língua portuguesa não integra até a publicação deste trabalho -as seis línguas oficiais da Organização das Nações Unidas (ONU), inexistindo, portanto, versão em português advinda da própria instituição, optou-se pela extração do texto legal brasileiro.

60 soft law é fonte do direito que, à luz da transnormatividade, faz um diálogo com o hard law, flexibilizando suas disposições e servindo como instrumento para alcançar a melhor interpretação da norma jurídica. O soft law compõe-se, portanto, de princípios, leis-modelos e outros instrumentos que subsumem a tais características no comércio internacional. Para aprofundar o tema, ver Lauro da Gama e Souza Júnior. (SOUZA JÚNIOR, 2006, p. 245-250).

7 Nos comentários oficiais aos Princípios UNIDROIT (disponível em: https://www.unidroit.org/english/principles/contracts/ principles2016/principles2016-e.pdf). Acesso em 06/06/2020) a anotação relativa à natureza mandatória do princípio é 
Neste contexto, o Direito não pôde ficar alheio e as normas jurídicas passaram a ser interpretadas considerando a boa-fé não apenas como princípio, mas sim, como regra jurídica de aplicabilidade necessária. Essa transmutação suscita a ressignificação da autonomia da vontade no âmbito dos contratos internacionais, causando, em cascata, efeitos nos negócios jurídicos transnacionais contemporâneos: a autonomia da vontade já não é mais ilimitada.

Esta nova concepção de contratar e, portanto, do negócio jurídico é ainda mais desafiadora, considerando que a boa-fé implica, inexoravelmente, um agir negocial emoldurado na valorização jurídica da confiança e cooperação - ainda que em parâmetros mínimos, ou mesmo passivos.

O presente estudo científico, imbuído da vontade de contribuir para a materialização desse papel da boa-fé nos negócios transnacionais, se propõe, assim, a analisar as alterações percebidas pela boa-fé até sua atual formatação, compreendendo-as, tanto na causa, quanto na consequência.

Para este fim, este artigo é estruturado de forma a analisar e, tanto quanto possível, responder as problemáticas contemporâneas em torno da boa-fé. Inicia-se pelo estudo da aludida "mutação jurídica" da boa-fé objetiva, bem como seu atual status nas relações comerciais transfronteiriças, sob a égide de um recorte determinado: a CISG.

Em seguida, estudam-se algumas das implicações que a ressignificação da boa-fé suscita aos negócios jurídicos transnacionais atuais, para aferir seus possíveis impactos nas contratações dali derivadas, e o que, por consequência, se cobra dos players do comércio internacional em nome da boa-fé objetiva. Aponte-se que essa análise se deu, em especial, à luz de conclusões obtidas no trabalho científico desenvolvido por Renata Alvares Gaspar e Mariana Romanello Jacob (ALVARES GASPAR; JACOB, 2015) ${ }^{8}$, relativo à persecução de contornos materiais em comum da boa-fé objetiva no comércio transnacional que, sendo plural, cobra segurança jurídica através de pontos de convergência quanto ao que se considera boa-fé objetiva nos negócios internacionais.

Ao final do presente esforço científico, encontra-se uma reflexão em forma de conclusões sobre o direcionamento para onde o repensar da boa-fé objetiva conduz neste âmbito das relações jurídicas e, ainda, suas implicações nas relações comerciais do mundo global, inclusive no modo de agir dos sujeitos que atuam e geram essas relações.

Para tanto, fez-se uso do método indutivo, o qual moldou os esforços para a promoção de uma análise realizada primeiro sobre um recorte específico, leia-se, a boa-fé à luz da CISG, para que a partir daí fosse ampliada para uma avaliação de conclusões gerais, ou seja, de quais as implicações da boa-fé nos negócios jurídicos transnacionais atuais. Isso demandou conhecer, em paralelo, a construção da limitação da autonomia da vontade das partes, justamente no âmbito contratual; o que, em princípio, pode se afigurar como um paradoxo. 0 resultado da pesquisa então, se apresenta neste texto, como forma acadêmica de contribuir

elucidativa e corrobora o entendimento que este estudo sustenta: "O dever das partes de agir de acordo com a boa-fé e a negociação justa é de tal natureza fundamental, que as partes não podem, contratualmente, excluí-la ou limitá-la." (p. 20-21, tradução nossa do original em inglês).

8 Trata-se de um trabalho de pesquisa concluído pelas referidas autoras em sede de resultado final de pesquisa institucional de Iniciação Científica (ano 2014-2015) pela Pontifícia Universidade Católica de Campinas, modalidade bolsa FAPIC/Reitoria. 
ao debate. Como método de procedimento, adotou-se pesquisa bibliográfica, majoritariamente doutrinária, porém com alguns contributos da normatização e diálogo de fontes internacionais, bem como da jurisprudência, sobretudo para corroborar a indução ora adotada como método.

Importa dizer, ainda, que este estudo está emoldurado pelo olhar metodológico dos direitos humanos, aqui compreendido como esforço civilizatório para a promoção e manutenção das relações sociais - e sobretudo comerciais - sob o manto protetor da dignidade humana ${ }^{9}$.

Esse olhar metodológico implica afirmar que num mundo globalizado, em que as diferenças estão na ordem do dia - o que significa que os atores desta sociedade global se encontram constantemente pelas suas diferenças culturais e, portanto, jurídicas - o Direito experimenta desafios diários, para não só garantir a segurança jurídica dos negócios transnacionais, como para, nesta mesma missão, assegurar, de forma condicionante, que as pessoas - e suas dignidades - não encontrem na liberdade de contratação um artifício legal de violação de sua condição de pessoa na sociedade atual, marcada e emoldurada pela expansão do comércio transfronteiriço, que em não raras ocasiões trata as pessoas e seus direitos, como elementos de negociação, em cálculos de custos e lucros.

Trata-se, pois, de pensar e estudar o direito através de um olhar metodológico que ressignifica os direitos individuais a partir dos direitos coletivos ${ }^{10}$. 0 presente artigo, escorado nessa ressignificação, faz uso do aludido olhar metodológico com foco em instrumentalizar o direito a alcançar pontos de convergência entre sujeitos e sistemas plurais, sem que se perca o direito à diferença, tudo na tentativa de, ao fim e ao cabo, prover equilíbrio e equidade nas relações jurídicas transnacionais, a que todo sujeito possui direito, eis que, independentemente de diferenças e pluralidades, são sempre e inerentemente iguais em dignidade.

Ao mesmo tempo, ao se refletir, no final desta pesquisa, sobre o que representam os atuais alcances e limites da boa-fé objetiva nos negócios internacionais, a escolha pelo olhar metodológico à luz dos direitos humanos permite chegar a conclusões que transcendem a esfera das relações jurídicas puramente negociais, e, também por isso, sua adoção como condutor metodológico do estudo.

9 Essa metodologia foi usada por Renata Alvares Gaspar (ALVARES GASPAR, 2016) que, ao tratar da arbitragem mista para o investimento estrangeiro, constata que o árbitro, tribunal arbitral ou juiz não pode desconsiderar, ao aplicar o regime jurídico adequado, o direito ao desenvolvimento como direito humano e fundamental, de modo que esse olhar deve pautar metodologicamente tanto a leitura hermenêutica do direito, como sua aplicação.

10 Esta ótica repousa, mormente, sobre as inferências obtidas do estudo desenvolvido por Jürgen Habermas (1997) que, ao tratar de política, poder e direito, relaciona, dentre outros aspectos e conceitos, a autonomia privada e pública, e os direitos humanos à luz de suas legitimidades em um sistema democrático. Para aprofundamento do tema ver Jürgen Habermas (HABERMAS, 1997). 


\title{
2. BOA-FÉ: DE PRINCÍPIO REGENTE À NORMA COGENTE
}

Em perspectiva histórica ${ }^{11}$, como visto ${ }^{12}$, não foi na contemporaneidade, nem com a expansão do comércio em escala global e multiconectado, que se passou a demandar uma mutação no princípio da boa-fé como regra a reger as relações jurídicas de natureza mercantil.

Ocorre que o comércio transfronteiriço, já nas raízes da lex mercatoria ${ }^{13}$, sobretudo em função do processo pelo qual se molda - usos e costumes -, colabora sensivelmente para a construção de um atuar de boa-fé enquanto dever nas relações. De tal forma que antes mesmo de constar expressa na CISG, "o princípio da boa-fé vinha sendo aplicado nas relações comerciais internacionais como 'princípio geral de direito da lex mercatória'." (MARTINS-COSTA, 1995, p. 121)

Na mesma linha, Frederico Eduardo Zenedin Glitz, ao tratar de costumes, usos e práticas de negócio, traz como exemplo, a boa-fé como espécie de ética própria da classe mercante e seu status de costume internacional no seio dessas relações:

\begin{abstract}
Basta, por exemplo, imaginar que o princípio da boa-fé de negócios já foi identificado como convenção social típica entre mercadores (como se fosse uma ética restrita a uma classe, e daí outras afirmações: garantida pelo "fio do bigode" e "acordo de cavalheiros"), passando a ser considerada típico costume internacional (por exemplo, consagrada pela CISG) [...] (Tradução nossa do espanhol). (GLITZ, 2012, p. 156)
\end{abstract}

A ética imposta pela boa-fé nas relações mercantis já dessa época permite inferir que, pelas práticas comerciais tidas nesse contexto, já se sabia que deixar as partes de um negócio jurídico ao alvedrio de uma liberdade irrestrita pode levar, em função dos jogos de poder que emolduram tais relações, à opressão de algum dos agentes, que por razões diversas, veem sua liberdade minimizada, senão totalmente sublevada, pela vontade exclusiva do outro, que por razões extra ou metajurídicas, impõe de forma "natural" suas decisões negociais em detrimento de outras.

Logo, repita-se por ênfase, a boa-fé em sua feição objetiva, na qualidade de princípio norteador de relações jurídicas no cenário do comércio internacional não teve origem na contemporaneidade, nem tampouco nas inúmeras consequências da globalização. Não obstante, o contexto da globalização colaborou sensivelmente para que a acepção e o papel do princípio da boa-fé fossem modificados em relevância e cogência, deixando de apenar orientar o comportamento humano nessas relações, para tornar-se um dever geral de comportamento materializado em regra jurídica.

11 Frise-se que não é escopo desta pesquisa empreender uma imersão na história da boa-fé, sendo, ainda, temerário arriscar-se, nessas breves linhas, a essa missão, tamanhas as eméritas obras que já trataram deste tema de forma minuciosa e com o escopo determinado. V. exemplificativamente: Judith Martins-Costa (MARTINS-COSTA, 2000); António Menezes Cordeiro (MENEZES CORDEIRO, 2011); Edward Allan Farnsworth (FARNSWORTH, 1963).

12 V. nota 2

13 A existência de uma "primeira", uma "nova" e até da própria lex mercatoria não tem opinião pacífica na doutrina. Frederico Eduardo Zenedin Glitz (GLITZ, 2012, p. 126-132), por exemplo, sistematiza uma série de distinções entre a primeira lex mercatoria e a contemporânea. Contudo, não sendo este o objeto do trabalho, não se fará essa discussão, apenas se admitindo a existência de um regramento próprio de empresários transnacionais, tema assente para os juristas, cuja terminologia, nesta pesquisa, não se faz necessário explorar. 
Quando a expansão do comércio transfronteiriço atinge escalas globais e passa a unir ou ligar culturas distintas - às vezes diametralmente opostas -, numa interconexão de pluralidades sem precedentes, a boa-fé como limitador da autonomia de partes passa a ser desafiada, para que alguns agentes do comércio não fossem submetidos a outros, cuja vontade estava arvorada num maior poder econômico.

Isso porque é sabido que não se contrata no Brasil, como se contrata no Japão, assim como não se contrata no Marrocos, como se contrata nos Estados Unidos. Esse cenário plural, portanto, acarreta igualmente um novo nível de insegurança jurídica, que, como sempre, cobra resposta do Direito.

Sem dúvida uma das respostas - e talvez a mais complexa e importante - foi a redefinição do conceito da boa-fé, provocando a mutação de sua natureza para dotá-lo de coerção, num divisor de águas mais uma vez desconhecido - em magnitude e proporção - pela história do Direito Internacional Privado: deixa de apenas iluminar o caminho e torna-se o próprio caminho a ser seguido, através de uma nova concepção, não sendo mais aquela vinculada a decisões subjetivas dos atores do comércio e sim, vinculada ao comportamento objetivo de tais atores.

Não obstante os esforços, ao longo do tempo, no intento de limitar a autonomia irrestrita de vontade das partes e o oportunismo que essa ilimitação gera nos agires comerciais além-fronteiras, o divisor de águas contemporâneo se encontra na materialização jurídica - e aqui começa a essência desse trabalho científico - da Convenção de Viena sobre Compra e Venda Internacional de Mercadorias de 1980, que se gabou por ser o esforço histórico-jurídico da cogência de maneira uniformizada das práticas costumeiras consolidadas do comércio internacional, recebendo ainda, como aduz Vera Jacob Fradera (FRADERA, 2011:23), inspiração de outros modelos já positivados, como o direito alemão dos contratos e o Uniform Commercial Code estadunidense, sob os auspícios da Comissão das Nações Unidas sobre o Direito do Comércio Internacional (UNCITRAL, sigla em inglês) ${ }^{14}$; tal instrumento normativo, como ensina a referida autora, é resultado e um movimento doutrinário e político oriundo, dentre outras questões, da necessidade de "se criar soluções de adaptação a um meio ambiente onde a diversidade de sistemas jurídicos está sempre presente e a instabilidade econômica e política é, o mais das vezes, a regra" (FRADERA, 2011, p. 2).

Como instrumento de vocação transnacional e, portanto, pretensamente compatível com distintos sistemas jurídicos, a CISG é atualmente a maior compilação codificada pelo hard law ${ }^{15}$ de regras uniformes do comércio internacional, possuindo elevado grau de aceitação (haja vista o número de signatários ${ }^{16}$ ). E mais: sendo uma Convenção, sua cogência para quem a ratifica é ineludível ${ }^{17}$ e, portanto, menos suscetível a debates tântricos, quando

14 Não se pode olvidar que a UNCITRAL, como organismo vinculado à ONU, é responsável pelo desenvolvimento do comércio internacional, a partir da ótica deste, ou seja, como instrumento de manutenção da paz mundial, perspectiva que é aplicada no todo deste trabalho.

15 Diz-se com ênfase "codificada pelo hard law" para distinguir da "codificação" pleiteada pela nova lex mercatória através de instrumentos de soft law, âmbito ao qual a CISG não pertence, eis que instrumento clássico de hard law.

1693 signatários, até a data de publicação deste trabalho. Rol de signatários disponível em: https://uncitral.un.org/en/texts/ salegoods/conventions/sale_of_goods/cisg/status. Acesso em: 03 jun. 2020.

17 Ressalvado tão somente se, num caso concreto, as partes adotarem seu artigo 6 que permite o afastamento da CISG, mesmo sendo um tratado ratificado: "As partes podem excluir a aplicação desta Convenção, derrogar qualquer de suas disposições ou modificar-Ihes os efeitos, observando-se o disposto no Artigo 12.". 
comparado aos usos e costumes, que, embora regras, concedem mais espaço para volatilidades e discussões de fundo.

Para fazer jus ao que lhe deu ensejo, uma das formas de a CISG brindar a possibilidade de vários sistemas reunirem-se debaixo da mesma regulamentação foi a adoção de princípios e cláusulas abertas que permitissem, pela vagueza, flexibilização e identidade. Judith Martins-Costa, ao constatar alguns dos fatores que colocam a CISG como fonte bem-sucedida no escopo de permitir o desenvolvimento de um direito contratual uniforme, enfatiza que:

Entre esses vários vetores está, por igual, a circunstância de a Convenção ter abrigado fértil principiologia, por forma a permitir - em razão do próprio caráter de certos princípios que adota - a sua própria constante flexibilização, reduzindo, por essa via, o imobilismo que marca e enrijece, em regra, os textos regulamentares. (MARTINS-COSTA, 1995, p. 118)

Uma das cláusulas abertas adotadas foi a da boa-fé objetiva no artigo $7^{\circ}$ da Convenção, o qual impõe, na interpretação da CISG, que se leve em conta a necessidade de assegurar o respeito da boa-fé no comércio internacional. Portanto, de forma clara, expressa e uniforme, a sociedade internacional decidiu adotar um importante limitador à vontade dos atores do comércio, o que não passa despercebido por eles e pelos juristas que a esta área da vivência humana se dedicam.

Dito de outro modo, embora com características próprias de princípio - chamada a desempenhar funções de interpretação, concretização e controle (FRADERA, 2011, p. 14) - a boa-fé agora definitivamente objetiva, ganha com esse mandamento, status de norma cogente, porque ordenada por uma Convenção - vale dizer, a forma clássica de codificar o direito internacional - celebrada tanto para dar guarida a qualquer player do comércio transnacional, independentemente de sua origem jurídica, quanto para limitar a atuação de atores mais poderosos, tentados a impor seus desejos e vontades aos demais parceiros deste jogo. Logo, a boa-fé, com status de norma cogente no âmago da CISG, torna-se obrigatoriamente tão global, quanto o são as relações comerciais que lhe demandaram.

De natureza coercitiva, como regra de conduta imperativa, a boa-fé, nas relações que estiverem sob o guarda-chuva da CISG, atua como orientadora e controladora do comportamento das partes. Desse modo, portanto, adquire verdadeira força de contenção de vontades ilimitadas entre os agentes do comércio.

Nesse sentido, é elucidativo o rol organizado por Judith Martins-Costa (MARTINS-COSTA, 1995, p. 121-122) quanto aos artigos da Convenção de Viena que são impactados pela boa-fé estampada no artigo $7^{\circ}$, no que tange a criação de direitos e deveres laterais dos contratantes (e, portanto, contenção de posturas ilimitadas como aqui se sustenta), como, por exemplo, o do art. $77^{18}$, que prevê o dever de cooperação para o bom adimplemento do contrato e da tomada das medidas necessárias para não aumentar o seu prejuízo (o qual, é, aliás, incorporação do duty of mitigate, próprio do direito anglo-saxão).

Ao final, a renomada autora conclui:

18 "Artigo 77: A parte que invocar o inadimplemento do contrato deverá tomar as medidas que forem razoáveis, de acordo com as circunstâncias, para diminuir os prejuízos resultantes do descumprimento, incluídos os lucros cessantes. Caso não adote estas medidas, a outra parte poderá pedir redução na indenização das perdas e danos, no montante da perda que deveria ter sido mitigada.". 
Como se observa, é extenso o rol dos deveres que decorrem da boa-fé e cuja quebra pode conduzir inclusive à configuração do inadimplemento contratual, mesmo quando prestada a obrigação principal. Constitui, nesse sentido, uma fonte de otimização da conduta contratual, tendo em vista o pleno e eficaz atendimento da finalidade para a qual foi criado o vínculo, qual seja, o adimplemento contratual. (Grifo da autora) (MARTINS-COSTA, 1995, p. 122)

Vale comentar que a compreensão da boa-fé como necessária às relações comerciais e sua consequente imposição coercitiva não ocorre apenas na esfera transnacional. Nos Estados Unidos, por exemplo, país pertencente à família da common law, o fenômeno fica nítido com a materialização do dever de boa-fé nas relações comerciais pela sua codificação no Uniform Commercial Code ${ }^{19}$. Luciano Benetti Timm ensina que o princípio da boa-fé objetiva "não deriva propriamente da tradição da Common Law, mas da legislação, ou seja, do UCC, parágrafo $1^{0}-304$, combinado com parágrafo 1-201(20)". (TIMM, 2012, p. 536)

A força do direito à liberdade nesse sistema jurídico e da relação contratual pautada intensamente na eficiência econômica não davam margem à visão cooperativista e garantista própria da boa-fé de outras famílias jurídicas (em especial, civil law e direito islâmico). Harold Dubroff (DUBROFF, 2012, p. 571) constata que antes da adoção do UCC, a common law da maioria dos estados estadunidenses ainda não havia reconhecido um dever implícito da boa-fé, e que se tratava de uma criação da common law de Nova lorque (uma jurisdição, aliás, não conhecida por sua abordagem liberal à interpretação de contratos).

Desse modo, a imposição geral da boa-fé veio a ocorrer com a força da lei, num reconhecimento explícito da sua essencialidade aos negócios jurídicos ${ }^{20}$. A lei-modelo representou um divisor de águas porque passou a incluir a obrigação de boa-fé no âmbito de todos os contratos comerciais e no meio século seguinte à promulgação do UCC o dever implícito da boa-fé objetiva acaba sendo aceito como parte da common law na maioria dos estados (DUBROFF, 2012, p. 571).

Uma vez compreendido que, ademais de regra jurídica imperativa à luz da CISG, num contexto em que seu conceito e alcance não são unívocos, como visto pelo exemplo acima, importa agora investigar, portanto, seu alcance e seus limites nos negócios internacionais. E tal investigação deve considerar as diferentes perspectivas deste instituto jurídico, para ao final, viabilizar um conceito universalizante - e/ou estandarizado - capaz de contemplar todas as diferenças e toda a proteção a que esta norma está vocacionada. Isso porque, nenhuma cláusula em teoria e forma é autenticamente válida se carente de contornos materiais hábeis à sua aplicação prática.

19 Lei-modelo promulgada em 1951, pela National Conference of Commissioners on Uniform State Laws e pelo American Law Institute.

20 Ressalta-se, nesse ponto, que, como ensina Harold Dubroff (DUBROFF, 2012, p. 564-571), houve, sim, o reconhecimento jurisprudencial de sua existência implícita nos contratos domésticos (o autor menciona o caso Kirk La Shelle Co. v PaulArmstrong Co., 1933, citado frequentemente como o principal caso inicial quanto ao dever de boa-fé), porém de forma mais pontual e localizada. 


\section{ALCANCE E LIMITES ATUAIS DA BOA-FÉ}

Como visto, a elevação da boa-fé objetiva à regra cogente dá passo a uma fase emblemática na regência jurídica das relações comerciais transfronteiriças, plurais por natureza. Esse importante passo, porém, se torna vazio se os players do comércio internacional - vale dizer, os diretamente impactados pelas disposições da CISG - não encontrarem, na boa-fé ali estampada em teoria, a feição de identidade quando da sua aplicação prática; com isso Ihe faltará credibilidade e, em "efeito dominó" e um dos piores cenários, Ihe faltará a legitimidade da regra jurídica dela decorrente.

Diz-se um dos "piores cenários" porque, sobretudo num cenário onde a máxima é o consenso, a ausência de legitimidade provoca praticamente a perda de vigência concreta da norma, uma vez que, malgrado assente em tratado ou convenção, se não sabido seu conteúdo, sequer há como esperar a sua prática. Desenhar-se-ia, assim, um cenário em que as partes tenderiam à aplicação do artigo $6^{\circ}$ (v. nota 15) com o intuito de afastamento da Convenção.

Nesse ponto, é importante um breve parêntese para enfatizar que o critério da legitimidade da norma como elemento essencial de sua vigência (transcendendo a mera legalidade) é própria de uma visão garantista, adotando-se como fim último a proteção da dignidade humana (coadunando-se com o condutor metodológico aplicado neste trabalho).

Isso porque, desde outras perspectivas, o critério da legitimidade não é necessariamente aplicado. Segundo Ricardo Manoel Oliveira Morais e Adriana Campos Silva, por exemplo, o "fato de o liberalismo adotar o critério da utilidade como princípio de valoração faz com que nenhuma instância, nem mesmo as legislações infraconstitucionais, tenha de se submeter ao critério da legitimidade"21 (MORAIS; SILVA, 2017, p. 240).

Sob a perspectiva da legitimidade, portanto, faz-se necessário encontrar para a boa-fé estampada na CISG como regra jurídica, um conceito que alcance dita legitimidade entre todas as partes ali aderentes.

Para isso, é importante que tal identificação transcenda seus contornos materiais genéricos a fim de encontrar as circunstâncias jurídicas específicas e criteriosamente estabelecidas, que guardem legitimidade, em função do reconhecimento mútuo, de todos os atores envolvidos, considerando o elemento de internacionalidade essencial desta Convenção, para que possa fazer efetivamente sentido. Com isso, dota-se a boa-fé de legitimidade para todos os atores que dela tiverem que se valer como regra jurídica de seus negócios, blindando-a, o quanto seja possível, de distorções possíveis oriundas da diversidade de ordenamentos em questão.

Nesse sentido, Francisco Augusto Pignatta ao tratar da aplicação geral das regras da CISG é claro ao aduzir que "para obter a uniformização da aplicação da Convenção, o juiz deverá estar atento a noções internacional de caráter uniformizador e evitar noções de caráter nacional contidas em seu direito interno.". (PIGNATTA, 2011, p. 23)

21 Não se quer dizer que outras óticas não visam também a proteção à dignidade humana, conforme os próprios meios científicos estruturantes. Apenas se pretende esclarecer que, dada a metodologia aplicada neste trabalho, a adoção do critério da legitimidade da norma é mandatória. 
Ou seja, parece fundamental, para o bom funcionamento da CISG, identificar qual a conduta real que, nas práticas do comércio considerado na pluralidade da Comunidade Internacional ${ }^{22}$, todo e qualquer ator reconhece como tal e, portanto, reconhece como digno de observância social e jurídica em nome da boa-fé objetiva, nas relações comerciais transfronteiriças.

E esta tarefa perde a simplicidade, se entendermos que a boa-fé objetiva, para os players do comércio internacional, é um importante limitador de sua suposta autonomia irrestrita nos negócios jurídicos que se inserem.

É possível afirmar - com base no trabalho científico desenvolvido por Renata Alvares Gaspar e Mariana Romanello Jacob (ALVARES GASPAR; JACOB, 2015) ${ }^{23}$ - que a resposta está nos denominadores comuns das diversas famílias jurídicas existentes na Comunidade Internacional, reveladores de que há sim um comportamento comum entre os players dos negócios internacionais, que pode ser encontrado na observância e no percorrido de um caminho metodológico específico.

O caminho adotado pelas aludidas autoras se refere ao estudo desde o interior dos sistemas, considerando as especificidades de suas regulamentações internas sobre o tema em análise, a partir da metodologia da hermenêutica diatópica, popularizada por Boaventura de Sousa Santos (SANTOS, 1997) ${ }^{24}$; tal metodologia, como é sabido à saciedade, compreende-se, na ótica que interessa a esta pesquisa, em maximizar-se as diferenças dos sistemas jurídicos objeto da análise para, num caminho inverso, identificar-se suas convergências.

Conforme revela o referenciado trabalho científico, esta, tampouco, é tarefa fácil, pois sua realização implica, necessariamente uma observação dos sistemas jurídicos a partir de "dentro" e não de "fora para dentro". Isso porque, de "fora para dentro", pesquisar-se-ia, desde o início, um sistema a partir de outro, provocando um estudo comparado, que, para os fins do que se pretende não se adequaria, eis que levaria a uma análise dos sistemas a partir de pré-conceitos que o investigador imprimiria, desde os dogmas de seu próprio sistema. Esta aproximação metodológica requer cuidados importantes, sob pena de ser atentatória no fundo e na forma -, às verdades materializadas nos sistemas jurídicos analisados.

Depois, portanto, de se ter passado um verdadeiro "pente fino" pela concepção das boas-fés no referido trabalho cientifico ${ }^{25}$, a resposta encontrada pelas autoras apontou como denominador comum na figura jurídica do abuso de direito, sendo este considerado desde a corrente que o desenvolve a partir da boa-fé e também o estuda em sua acepção objetiva. Tal fenômeno jurídico, como se sabe, reflete uma postura faltosa quanto à boa-fé, ou seja: aqueles que agem em abuso de direito, atuam comissiva ou omissivamente de forma contrária à boa-fé objetiva.

22 Utiliza-se, no todo deste trabalho, a expressão "Comunidade Internacional", conforme o avanço dos estudos sobre o tema. 0 termo "sociedade internacional" era utilizado e coerente com o paradigma vestfaliano da coexistência entre os Estados, tendo este paradigma sido superado (TOMUSHAT, 1999, p. 59-63).

23 V. nota 6

24 O ilustre jurista, partindo da concepção filosófica da hermenêutica diatópica inaugurada por Raimon Panikkar (PANIKKAR, 1984, p. 28), propõe essa modalidade hermenêutica para o fim de se encontrar uma concepção multicultural de direitos humanos. Inobstante, a essência do método pode ser transportado para outras perquirições, como se fez no trabalho aludido. Para aprofundar-se no tema, ver Boaventura de Sousa Santos (SANTOS, 1997, p. 23 e ss).

25 V. notas 6 e 24 
No caminho inverso, entende-se que o exercício regular do direito possui, para famílias jurídicas distintas ${ }^{26}$, a mesma conotação: age com boa-fé objetiva, aquele que atua regularmente nos limites do próprio direito. Tal conduta, numa relação por si só comercial, estabelecida, de essência, pela autonomia da vontade, já é significativa, uma vez que toda a liberdade tem o seu limite. Tal limite aponta, de forma universalizante, pelo menos no respeito ao outro com quem o negócio está sendo celebrado. Em outras palavras: não vale tudo para alcançar os objetivos comerciais.

Quando, porém, transporta-se tal ideia de boa-fé relacional para o cenário internacional de diferentes pluralidades, descentralizado e horizontal - onde, em tese, não deveria ser admissível a imposição de um ordenamento jurídico sobre outro e onde os atores que ali interagem devem ser obrigados a dialogar -, garantir que todos saibam e cheguem a um consenso de qual o limite da atuação de cada um faz com que o regular exercício do direito, como expressão universal da boa-fé objetiva, ganhe novas e emblemáticas proporções de relevância e funcionalidade prática.

Em nosso sentir, à luz das argumentações acima expostas e amparadas no citado trabalho científico, encontrar no exercício regular do direito um denominador comum relativo à boa-fé, como ostentação de comportamento não lesivo, conduz a um segundo denominador, este de fundo: o agir com alteridade.

Isso porque, a exigência de exercer regularmente os direitos como regra própria de boa-fé objetiva obriga, ainda que se fale em termos mínimos, que ao contratar, se leve em consideração não apenas o objetivo de se chegar, a qualquer preço, às vantagens individuais a partir da liberdade de atuação, tão própria do comércio internacional. É necessário também que as vantagens a serem obtidas pelo negócio estejam emolduradas pelo respeito às vantagens que o outro também está perseguindo, porque possui igual direito de perseguir.

Do contrário seria uma relação negocial desequilibrada e, portanto, juridicamente ilegítima, sob a ótica da metodologia adotada nesta pesquisa, qual seja, a moldura da proteção dos direitos humanos como ferramenta metodológica, fazendo-se luzir no resultado obtido.

Isso implica, portanto, na obrigação de, ainda que minimamente, levar em consideração o outro contratante. Obriga, desta forma, um agir, no mínimo responsável, ainda que não necessariamente colaborativo; isso quer dizer que as partes envolvidas têm, ao menos, de cooperar mutuamente, garantindo que a liberdade de sua atuação não interferirá, direta ou indiretamente, no direito de atuação que igualmente possui a contraparte.

Note-se que, na figura do abuso do direito, a alteridade é conditio sine qua non do negócio jurídico, uma vez que apenas se reprime o abuso quando o direito do outro foi atingido. A percepção do outro deixa, portanto, de ser conduta meramente moral ou subjetivamente ética; torna-se um imperativo, porque determinada por um instrumento jurídico que regula regras de condutas; portanto, norma cogente.

26 No trabalho científico em referência, em que esta análise foi levada a cabo, o estudo teve como recorte três lócus (que representam três sistemas jurídicos): i) Romano Germânico, excetuando o francês dadas suas especificações; ii) Islâmico, que neste âmbito a generalização pode ser entendida neste âmbito do comércio, haja vista que o Profeta tinha, por profissão, o comércio; e, iii) o Anglo-Saxão, com análise específica do subsistema estadunidense (considerando que o inglês é diferente em muitos aspectos). 
Para dar concreção a esse argumento, é possível pensar, como exemplo, o instituto da mitigação dos prejuízos ${ }^{27}$ tendo a boa-fé como seu fundamento. Christian Sahb Batista Lopes, ao buscar a fundamentação da norma de mitigação no direito brasileiro, e colocando o abuso de direito como uma das possíveis fundamentações explica que ${ }^{28}$

Agir com boa-fé implica, no direito das obrigações, atitude cooperativa entre credor e devedor. Portanto, exerce abusivamente o direito à indenização o credor que pretender ser indenizado apesar de não ter agido conforme a boa-fé, ou seja, que não agiu de forma cooperativa para evitar a ocorrência dos danos pelo emprego de esforços razoáveis. Diante do inadimplemento de uma obrigação, a boa-fé impõe que o credor colabore com o devedor e evite danos ao seu próprio patrimônio, de forma a evitar o desperdício de recursos econômica e socialmente relevantes. Havendo possibilidade de evitar o prejuízo por meio de esforços razoáveis, a conduta socialmente esperada do homem probo é que aja de forma a que tais danos não ocorram. Se, no entanto, o credor viola tal norma imposta pela boa-fé e posteriormente pretende obter reparação pelos danos sofridos, o exercício ao seu direito à indenização é abusivo, pois excede manifestamente os limites traçados pela boa-fé. (Grifo nosso) (LOPES, 2011, p. 158)

Deduz-se, assim, que a contraparte, mesmo que inadimplente, é colocada, em última análise, como medida do direito do credor, sobretudo, dos limites a serem respeitados e que delineiam os perímetros para o abuso. Afinal, se ao titular do direito fosse franqueado ficar inerte e permitir que os danos chegassem a números vertiginosos estar-se-ia desconsiderando a figura do devedor, que estaria obrigado a reparações excessivas possivelmente não condizentes com o inadimplemento em si e que, com medidas movidas pela boa-fé do credor, poderiam ser evitadas. Assim, sob o manto da boa-fé objetiva, a percepção do outro passa a ser mandatória, e daí a alteridade aqui sustentada.

A alteridade é, portanto, o "mínimo" - o qual passará a ser referido como standard, não no sentido de juízo de valor, mas de qualidade indispensável dentro do princípio da boa-fé objetiva. Ter uma postura - ainda que passiva - de boa-fé numa relação contratual exige a percepção da contraparte como sujeito. Sujeito que é livre e, portanto, portador de direitos na mesma condição e ordem.

Sendo assim, a partir desta construção argumentativa realizada desde a análise da realidade objeto do estudo referido - que, como indicado, visou encontrar aquele denominador comum universalizador da concepção de boa-fé objetiva a fim de marcar seu limite e alcance nos negócios jurídicos internacionais -, se encontrou a figura do abuso de direito que, quando não observado, irradiará efeitos jurídicos nos negócios internacionais em questão, condicionando a aplicação das normas jurídicas incidentes no caso concreto, para demarcar e indicar responsabilidades e suas decorrências jurídicas.

Não obstante, o que aqui se definiu como standard, não impede que pouco a pouco seja diversamente apreendido quanto ao aumento de proteção e âmbito de compreensão, o que

27 Figura amplamente aceita no comércio internacional - ressalvadas especificidades e divergências quanto às consequências de sua aplicação em diferentes ordenamentos - a mitigação de prejuízos é, de forma geral, uma obrigação imposta ao credor que, prejudicado por um inadimplemento, deve evitar ou tomar esforços razoáveis a evitar as perdas e danos decorrentes do descumprimento, sob pena de não ser indenizado pelos prejuízos que poderiam ter sido mitigados. Sobre o tema ver Christian Sahb Batista Lopes (LOPES, 2011).

28 Destaque-se que o autor sustenta que o abuso de direito é um possível fundamento da mitigação de danos sobretudo como ratificação de que a mitigação tem seu fundamento na boa-fé, mas não o encara como o único fundamento. Para aprofundamento no tema ver Christian Sahb Batista Lopes (LOPES, 2011, p. 153-161). 
seria um ganho para a humanidade. Mas o que se defende aqui é que o "a mais" não é o ponto de partida. É no standard que começam a ser desvendados os contornos materiais comuns e novas expressões comportamentais globais da boa-fé objetiva contratual, podendo, assim, ficar descortinados seus alcance e limites no âmbito dos negócios jurídicos internacionais, permitindo a visualização mais clara dos comportamentos humanos e respostas jurídicas que outorgarão mais segurança jurídica às relações transfronteiriças.

\section{IMPLICAÇÓES NOS NEGÓCIOS INTERNACIONAIS}

Ressalvadas críticas ou reverências, debate que não cabe neste espaço, muito embora tangencie a análise aqui realizada, é fato notório que o modelo capitalista é não só o canal essencial para a obtenção de lucros, como também para sua maximização, a partir das vantagens individuais obtidas num livre mercado ${ }^{29}$. Neste espaço, contemporaneamente, trava-se uma disputa entre a liberdade como algo absoluto e como algo cuja relativização é necessária.

Isso porque, a priori, a busca incessante pela maximização das vantagens individuais (que se materializa no lucro) pode abrir espaço para pensamentos e posturas que clamem a liberdade individual como ilimitada, por aqueles que considerarem que a lucratividade máxima só pode ser obtida se a liberdade de atuação também for máxima, ou seja, sem as restrições e, portanto, os "entraves" que o Direito impõe quando relativiza a liberdade individual em nome do direito alheio.

Assim, colocar em xeque o absoluto da liberdade individual - considerando que o sistema capitalista encontra sua melhor realização nas liberdades totais (fictícias por natureza) -, impondo-Ihe os limites intrínsecos da relativização revela-se como a única possibilidade de que tal maximização ocorra, porém, convivendo com a (res)significação dos direitos individuais a partir dos direitos coletivos. Nesse sentido, Jürgen Habermas ensina que:

A conduta consciente da vida da pessoa singular mede-se pelo ideal expressivista da auto-realização, pela ideia deontológica da liberdade e pela máxima utilitarista da multiplicação das chances individuais de vida. Ao passo que a eticidade de formas de vida coletivas mede-se, de um lado, por utopias de uma convivência não-alienada e solidária no horizonte de tradições assimiladas conscientemente e continuadas criticamente, de outro lado, por modelos de uma sociedade justa, cujas instituições de configuram de modo a regular expectativas de comportamento e conflitos no interesse simétrico de todos os atores; uma variante disso são as ideias do aumento e distribuição justa da riqueza social, cultivadas no Estado do bem-estar. (HABERMAS, 1997, p.132)

Consiste, em suma, na única possibilidade de garantia em matéria de realização e de construção de uma ética coletiva.

Este debate não passa, portanto, incólume pela regulamentação da boa-fé em sua faceta objetiva que, como regra jurídica cogente impõe, para gosto ou desgosto, limites à 
maximização de lucros advinda de vantagens unicamente individuais, uma vez que obriga a consideração do outro, da contraparte do negócio, cujo desprezo ou desrespeito não são permitidos, nem relevados pela ética que como visto, a nosso sentir, constrói-se cada vez mais de forma coletiva.

Importante notar que quando se luta pelo acúmulo, a tendência, inexoravelmente, é focar-se em si mesmo. A eficiência individual, em tese, teria que ser levada ao extremo para a suposta garantia sistêmica. Isso porque, como se sabe, dentro do conceito de capitalismo, não existe acúmulo que seja coletivo.

Numa relação negocial, isso é evidente; cada parte, no mais das vezes se decanta por cuidar do que é seu, resguardando seus próprios interesses e voltando-se para tudo aquilo que lhe abrirá caminho na perquirição do "pote de ouro" que se encontra no resultado das negociações. Neste aspecto o lucro a qualquer preço, é, em nosso sentir, entendido de forma indevida, pois interpretado puramente como eficiência negocial. Assim, à primeira vista, a chamada "lei da sobrevivência" parece conduzir cada vez mais ao lema do "cada um por si".

Não por outra razão, repassando toda a realidade acima exposta à luz da CISG, se pode compreender que nas relações contratuais internacionais, ao se impor o princípio da boa-fé objetiva como regra cogente, o cenário que se depara ganha outros contornos e, portanto, outra percepção do ponto de vista jurídico e - como não podia deixar de ser - do ponto de vista humano.

Isso porque, sendo o exercício regular de direito - e o dever de alteridade daí decorrente - o standard da boa-fé objetiva transnacional, o que todo esse contexto tem mostrado é que, ao fim e ao cabo, a construção do lucro, a princípio estritamente individual, só é de fato atingida se ocorrer com o olhar sobre o outro; mediante a observância desta ética coletiva. Isso será a forma jurídica de dotar de legitimidade as operações negociais de maneira sustentável.

Assim, onde, por lógica do sistema, tanta tendência há para o individualismo, o standard enquanto regra de conduta imperativa de uma das maiore ${ }^{30}$ Convenções de transações transnacionais do mundo, obriga o desvio do foco - ao menos em parte - e convoca para um agir panorâmico, em que constatar o papel, a posição e o direito do outro deve obrigatoriamente condicionar o seu próprio agir.

Impõe-se, assim, à ética - intrínseca da boa-fé contratual - caráter de responsabilidade, onde o direito de liberdade no agir possa ser exercido em sua amplitude, mas nunca fora dos seus contornos limitadores; ética responsável no sentido de que considerar o outro seja condição para a própria atuação em cada negócio.

E tudo o que foi dito cabe, ainda, dentro deste próprio sistema. No modelo econômico atual a figura da contraparte (vendedor, comprador, fornecedor, prestador de serviço, transportador e demais players empresariais) é tão conditio sine qua non à obtenção do lucro, como o são os outros fatores de produção e de mercado. A figura do "outro", portanto, não é novidade, já que desde as idas do mero escambo, teve-se essa ciência. 
O divisor de águas, porém, quando se tem a alteridade como premissa da norma cogente, resulta na imposição de descoisificar o outro ${ }^{31}$ e reconhecer a sua dignidade.

Não se pode, portanto, sob a égide da CISG, alocar objetivamente a contraparte como coisa, custo ou despesa, que admitem transação, aceitando-se, por exemplo, ferir o seu direito e apenas contabilizar a reparação dessa escolha. A reparação, claro, advirá, mas não só do dano causado; decorrerá também de inadimplemento da diretriz hermenêutica da própria Convenção e dos deveres que se originam da boa-fé, configurando, portanto, duas formas de inobservância.

Exemplo emblemático quanto a esse duplo inadimplemento se tem em recente julgado do Tribunal de Justiça do Rio Grande do Sul ${ }^{32}$ conhecido como "o caso dos pés-de-galinha" que, aplicando a CISG (e também os Princípios UNIDROIT), manteve a procedência de declaração da rescisão do contrato de compra e venda objeto do caso (compra e venda de pés de galinha congelados) e de restituição do valor determinados em primeira instância, com base no descumprimento da obrigação principal de entrega da mercadoria pela vendedora (art. 30 da $\left.\mathrm{CISG}^{33}\right)$, e também da própria boa-fé34:

no caso concreto, a declaração judicial de rescisão do contrato não se dissocia do reconhecimento de flagrante ofensa, pela vendedora / demandada, do dever das partes contratantes de proceder segundo os ditames de boa-fé, o cânone maior das relações internacionais regidas pela 'nova lex mercatoria' como se infere da leitura do art. 1.7 dos Princípios Unidroit e do art. 7(1) da Convenção de Viena de 1980 - esse último, aliás, constituindo um comando explícito aos Juízes (estatais ou arbitrais) que a aplicam. Com efeito, no intuito de criar uma uniformidade de regras para o tratamento destinado às relações comerciais internacionais, a Convenção de Viena de 1980 estruturou a noção de contrato a partir de dois pilares fundamentais, a saber, a autonomia privada e a boa-fé objetiva, da qual se pode extrair, entre outros, o dever das partes de atuar com lealdade negocial, a impor aos contratantes a compreensão de que o contrato de compra e venda internacional de mercadorias há de ser entendido como uma relação de cooperação entre os que dela participam. No caso concreto, como visto, houve frontal violação ao pilar da boa-fé, a ensejar a resolução do contrato, de conformidade com as demais normas a esse respeito ditadas pela Convenção. (Grifo do relator, p. 28-29 do julgado)

Infere-se que o descumprimento da obrigação essencial (no caso, a entrega de mercadorias) não foi considerada isoladamente como único inadimplemento a ensejar a resolução contratual. A boa-fé, reputada como comando ao julgador e um dos pilares da Convenção é computada na análise da conduta da vendedora perante à sua contraparte (compradora) e limita o segundo pilar: a autonomia da vontade.

31 Não se está dizendo que essa coisificação necessariamente acontece no modelo atual das relações de mercado. 0 que se intenta demonstrar é que a cogência do princípio da boa-fé objetiva por meio da CISG não dá margem ou abertura para que isso ocorra e reprime se ocorrer.

32 BRASIL. Tribunal de Justiça do Rio Grande do Sul. Apelação cível n 70072362940. 12a Câmara Cível. Apelante: Anexo Comercial Importação e Distribuição Ltda. - EPP. Apelada: Noridane Foods S.A. Relator: Des. Umberto Guaspari Sudbrack. Porto Alegre, RS, DJ: 14 de fevereiro de 2017.

33 "Artigo 30: 0 vendedor estará obrigado, nas condições previstas no contrato e na presente Convenção, a entregar as mercadorias, a transmitir a propriedade sobre elas e, sendo o caso, a remeter os respectivos documentos.".

34 Por não ser o escopo deste trabalho, não se citam aqui outros possíveis julgados sobre o tema (nacionais e internacionais). 
A limitação aqui esgrimida, evidentemente, não é aquela imposição íntima, em que as convicções subjetivas são atingidas. Isso, para a boa-fé objetiva, sequer importa. O que contará, para cumprir ou descumprir a CISG no art. $7^{\circ}$, será a conduta exteriorizada. É essa conduta que deve refletir uma atuação voltada, ainda que passivamente, para o outro, reconhecendo-o como tão sujeito de direitos quanto qualquer outro player do comércio internacional.

A implicação disso nos negócios jurídicos internacionais é brutal, porque, com a cogência do princípio da boa-fé, a obtenção do lucro ganha um novo caminho: para respeitar a Convenção aderida, necessariamente passa-se pela obrigação de transcender o exclusivismo do indivíduo, e compreender a posição do outro com o fim de respeitá-lo; para só assim, alcançar-se o tão visado "pote de ouro". Conquistá-lo, portanto, passa antes pela obrigação de encontrar na contraparte, o princípio e o fim do próprio direito.

E como implicação decorrente igualmente obriga a repensar o sistema desde outros limites conceituais, também, e sobretudo, de natureza econômica, pois maximizar as vantagens individuais dentro do livre comércio, encontra, querendo ou não, um limite que marca de forma indelével as transações internas e, no caso desta análise, internacionais.

A famosa "lei da sobrevivência", não só quanto ao lucro, mas quanto ao perdurar longevo dos negócios internacionais e internos - porque agem em conformidade às regras transnacionais -, ao fim e ao cabo, não nos conduz ao lema do "cada um por si". Para sobreviver e para durar, deve-se necessariamente considerar o outro e os direitos que igualmente possui. O fato é que a todos interessa a existência de bons contratantes - e aqui se entende como sendo os que atuam objetivamente como tais - e a segurança jurídica que disso decorre auxilia o Direito, tendo aqui a CISG como sua importante expressão a implementar esta sua eterna obsessão.

Um paralelo ilustrativo a esse panorama pode ser realizado a partir do trabalho desenvolvido por Renata Alvares Gaspar e Felipe Castro (ALVARES GASPAR; CASTRO, 2018) que, malgrado relativo ao Direito Internacional dos Investimentos - e, portanto, escopo diverso do presente artigo - traz notas conclusivas que são aplicáveis às diversas searas no mercado globalizado contemporâneo que visam a lucratividade, contemplados aí, dentre outros, tanto os investimentos estrangeiros, quanto os contratos comerciais entre particulares - estes diretamente abrigados pelo presente estudo.

Após exaustiva análise do contrato de inversão estrangeira e do alcance de sua segurança jurídica efetiva e legítima a partir de sua função social no cenário globalizado, os aludidos autores (ALVARES GASPAR; CASTRO, 2018, p. 334-339) concluem que a proteção à Cidadania e à dignidade humana são condições essenciais de manutenção de um mercado estável aos investimentos internacionais, eis que sem esse resguardo chegar-se-ia ao colapso social, afetando o ciclo do sistema necessário ao mercado financeiro sadio que desejam as inversoras. Nesse sentido,

(...) Como restou amplamente fundamentado neste trabalho, o investimento estrangeiro só pode desfrutar de efetiva segurança jurídica ao ingressar em um Estado nacional se estiver atento aos interesses da Cidadania, a fim de afastar a convulsão social capaz de desestabilizar toda a proteção aos efeitos econômicos do investimento realizado. A segurança jurídica que é conferida pelo Estado de Direito ao investimento estrangeiro só é realizável 
se observada a justiça e o bem-estar social; fora deste ditame, o risco ao investimento é imprevisível. (...) (ALVARES GASPAR; CASTRO, 2018, p. 334, grifo nosso)

Traçando-se um paralelo com o presente trabalho, infere-se que as relativizações e limitações encontradas hoje no mercado globalizado quanto à obtenção da lucratividade máxima e à autonomia da vontade demonstram que o Direito tem cada vez mais se configurado como instrumento para equalização de forças que, numa concepção liberal clássica, antes se contrapunham, e hodiernamente passam a ser entendidas - e pelo Direito assim reguladas - como simbióticas e necessárias à manutenção do próprio sistema.

No presente recorte, a CISG é a materialização desse mister e coloca o reconhecimento objetivo da dignidade humana do outro (materializado pela boa-fé contratual) como elemento cardeal para que os negócios jurídicos sejam considerados válidos e legítimos perante as grandes normas reguladoras do comércio transfronteiriço (por exemplo e neste estudo, a CISG).

E tudo isso, em relações plurais e multiconectadas, onde tanta diferença e - por consequência divergências - tendem a aparecer, abre espaço a um cenário promissor: a abertura para o que aqui se denomina de fraternidade nos negócios internacionais.

Ressalte-se, por ênfase, que a boa-fé objetiva não requer uma fraternidade afetuosa, íntima, subjetiva. Nem poderia, pois está é parte da esfera individual. Mas sim uma fraternidade que impõe a consideração do outro em sua intrínseca dignidade, a partir de ações negociais específicas, que denotem o respeito ao outro - e, portanto, a sua não coisificação -, para que a relação contratual seja realmente equilibrada e tão realizadora de tantos objetivos, quanto forem as pessoas nela envolvidas.

\section{CONSIDERAÇÓES FINAIS}

Todo o esforço científico que se costurou nessas breves linhas nos levou a identificar e compreender determinadas constatações pontuais sobre a boa-fé objetiva no âmbito dos negócios jurídicos internacionais, tendo a CISG como expressão paradigmática da cogência do princípio nessas relações no mundo global.

Constataram-se, de início, algumas razões da mutação da natureza jurídica do instituto da boa-fé objetiva: de princípio à regra de conduta imperativa.

Perquiriram-se, ainda, o alcance e os limites da boa-fé, aqui já em sua faceta objetiva e enquanto norma cogente, identificando-se que o esforço de encontrar seus contornos materiais importa, pois os sujeitos do comércio internacional são plurais e necessitam, como expressão de segurança jurídica, de conceitos minimamente comuns dos institutos jurídicos que regem suas relações no âmbito da Comunidade Internacional, numa aldeia global.

Como um dos denominadores comuns no que se refere ao alcance e limites buscados, identificou-se o exercício regular do direito como ato próprio de postura de boa-fé. Ou seja, no cenário transnacional, age conforme a regra de boa-fé objetiva, aquele que não abusa do próprio direito. 
Nessa linha, identificou-se, ademais, que a alteridade, como standard mínimo, impõe ao agente do comércio internacional que se obrigue a uma consideração minimamente objetiva pelo outro; ao reconhecimento, ainda que não subjetivo, de que o outro é tão igual no direito à liberdade de perseguir o lucro, como no dever de observar os limites dessa persecução.

Constataram-se, por fim, as implicações suscitadas pelo alcance e pelos limites da boa-fé nos negócios jurídicos internacionais, inferindo-se que a corrida pelo "pote de ouro" apenas aparenta ser individual. Mas que, no contexto do evoluir das relações negociais na Comunidade Internacional, não mais se corre - legitimamente - sem considerar o outro como parte integrante e igualitária dessa corrida; não mais se pode correr à revelia e ao desprezo objetivo da parte com quem negocia.

Pois bem. Tais constatações, embora de grande relevância, são, como dito, pontuais e é necessário, para alinhavar a costura que se pretende com o presente trabalho, nos esforçarmos a compreender o que, quando analisadas em conjunto, tais pontuações representam. Ou seja, o que significam em termos práticos e para onde - haja vista o inegável momento de transição da vida humana em todos os seus aspectos e perspectivas - todas essas verificações guiam as relações do comércio global.

Como já asseverado, a elevação formal da boa-fé objetiva como regra cogente, porque imposta expressamente pela CISG é, em verdade, um grande reflexo do que, na prática, já se exigia enquanto resposta do direito (usos e costumes) como forma de outorgar um mínimo de segurança jurídica nas aventuras (no mais das vezes de alto risco pela própria natureza das operações) do comércio internacional.

Significa dizer que a opção de obrigar sua observância jurídica decorreu de uma necessidade prática, que passou a ser percebida pelos próprios players do comércio internacional e encarada como condicionante para a coexistência de todos; com isso, sob o aspecto jurídico e objetivo, aludidos players se sujeitam tão somente aos desafios próprios das relações de mercado imersas no fair play e não à insegurança de comportamentos, omissivos e comissivos, que, quando exteriorizados, contrariam o que, num construir ao longo dos séculos, passou a se esperar de uma relação comercial justa e equilibrada.

Essa constatação leva-nos a outra: num contexto onde, pela lógica do sistema, tanta tendência há para as percepções e motivações individuais e exclusivistas, passar a obrigar - porque regra cogente - ao reconhecimento da outra parte, à compreensão de sua posição, seus direitos e deveres, e ao condicionamento dos limites da própria atuação tendo o outro como parte do parâmetro, representa uma superação ${ }^{35}$ de paradigma.

E a nosso sentir, tal superação abre, no fim das contas, um largo caminho para o que, como indicado, denominamos de fraternidade nos negócios internacionais. Uma fraternidade, por óbvio, em acepção objetiva, que não se insere, nem pretensamente, na esfera das religiões, das etnias e das escolhas individuais. Mas uma fraternidade que exige, em termos literalmente jurídicos, que todos os que estiverem atuando nos negócios comerciais transfronteiriços reconheçam o outro como igual em dignidade e que as condutas no próprio agir reflitam esse reconhecimento, ainda que, no íntimo, não exista.

35 Opta-se por utilizar o verbo "superar" no lugar da tradicional expressão "quebra de paradigma" porque se parte da premissa que as verdades anteriores passaram por um processo de amadurecimento, prático e teórico, resultando na superação da questão e não em sua quebra - que traz a conotação de destruição, rompimento. 
Fraternidade, portanto, que obriga que se reconheça, no outro, a mesma dignidade que se reconhece em si mesmo. E, num contexto onde o individual por tanto tempo aparentou ser a única regra e em que tanto se clamou pela liberdade, ter regras que imponham essa perspectiva de alteridade faz com que se possa pensar num passo em direção à fraternidade nas relações comerciais multiconectadas - o que pode ser entendido, a nosso ver, como um cenário de mudanças. Mudanças de percepções e de paradigmas, abrindo portas para a reanálise do sistema, do que é necessário, permitido e desejado para as relações comerciais e, claro, para o direito e sua tão perseguida segurança jurídica.

Por fim, mudanças que vão ao encontro do jus cogens internacional - ao qual pertencem os direitos humanos - com destaque ao primeiro de todos os comandos da Declaração Universal dos Direitos Humanos de 1948, sabido marco da normatização internacional relativa a direitos humanos na história mundial: "Artigo $1^{\circ}$ Todos os seres humanos nascem livres e iguais em dignidade e direitos. São dotados de razão e consciência e devem agir em relação uns aos outros com espírito de fraternidade." (Grifos nossos).

É possível inferir, portanto, que tais mudanças nas relações comerciais transfronteiriças, sobretudo quando postas em prática, viabilizam a concretização da proteção da dignidade, configurando-se como importante instrumento de implementação de tal resguardo e do espírito de fraternidade na seara dos negócios jurídicos transacionais.

Ao fim e ao cabo, um exercício de fraternidade exteriorizada que defendemos ser algo resultante do que o ex-presidente do Uruguai, José Mujica já havia alertado ${ }^{36}$ quanto à premência e imprescindibilidade de a humanidade pensar-se enquanto espécie, desprendendo-se do pensamento individualizado, unicamente enquanto país, enquanto classe social e enquanto indivíduo.

\section{REFERENCIAS}

Il Cumbre de la Celac - Declaración de La Habana - Discurso del Presidente de Uruguay José Mujica. Archipiélago - Revista Cultural de Nuestra América. Universidad Nacional Autónoma de México, v. 21, n. 83, 2014, p. 12-14. Disponível em: http://www.revistas.unam.mx/index.php/archipielago/article/view/55640/49356. Acesso em: 5 jun. 2020.

ALVARES GASPAR, Renata. Cooperação jurídica Internacional: reconhecimento de laudos estrangeiros em arbitragens mistas e as alterações promovidas pela Lei 13.129 de maio de 2015 neste âmbito. In: RAMOS, A. (Org.). Direito Internacional Privado: Questões Controvertidas. Belo Horizonte: Arraes, 2016, cap. 7, p.132-148.

ALVARES GASPAR, Renata; CASTRO, Felipe. Segurança jurídica, Função Econômica e Direito ao Desenvolvimento nos Contratos de Investimento Internacional: uma abordagem crítica à luz do caso Urbaser S/A e outro versus República Argentina. In: MENEZES, W. (Org.). Série Direito Internacional em expansão. 1ed. Belo Horizonte: Arraes, 2018, v. XIV, p. 323-341.

ALVARES GASPAR, Renata; JACOB, Mariana. A maximização da boa-fé a partir da CISG na contratação internacional: a sonância através das dissonâncias entre a civil law, a common law estadunidense e o direito islâmico. In: ENCONTRO DE INICIAÇÃO CIENTÍFICA, XX, 2015, Campinas. Anais do XX Encontro de Iniciação Científica - ISSN

36 Discurso realizado pelo ex-presidente do Uruguai José Mujica no II Cumbre da Celac em Havana, em janeiro de 2014. Transcrição do discurso encontrada em: http://www.revistas.unam.mx/index.php/archipielago/article/view/55640/49356. Acesso em: 5 jun. 2020. 
1982-0178. Campinas: PUC-Campinas, 2015. Disponível em: https://wl.sis.puc-campinas.edu.br/websist/Rep/ Sic08/Resumo/2015812_114954_435381879_resESU.pdf. Acesso em 5 jun. 2020.

BRASIL. Decreto n 8.327/2014 - Convenção das Nações Unidas sobre Contratos de Compra e Venda Internacional de Mercadorias - UNCITRAL, disponível em" http://www.planalto.gov.br/ccivil_03/_ato2011-2014/2014/ decreto/D8327.htm. Acesso em: 7 jun. 2020.

BRASIL. Tribunal de Justiça do Rio Grande do Sul. Apelação cível n 70072362940. 12a Câmara Cível. Apelante: Anexo Comercial Importação e Distribuição Ltda. - EPP. Apelada: Noridane Foods S.A. Desembargador Relator: Des. Umberto Guaspari Sudbrack. Porto Alegre, RS, DJ: 14 de fevereiro de 2017.

DUBROFF, Harold. The Implied Covenant of Good Faith in Contract Interpretation and Gap-Filling: Reviling a Revered Relic. St. John's Law Review, v. 80, n. 2, art. 3, fev. 2012. Disponível em: https://scholarship.law.stjohns.edu/ cgi/viewcontent.cgi?article=1200\&context=lawreview. Acesso em: 5 jun. 2020.

FARNSWORTH, Allan Edward. Good Faith Performance and Commercial Reasonableness under the Uniform Commercial Code. The University of Chicago Law Review, v. 30, n. 4, verão 1963. Disponível em: https://chicagounbound.uchicago.edu/cgi/viewcontent.cgi?article=3337\&context=uclrev. Acesso em: 5 jun. 2020.

FRADERA, Vera Jacob de. A saga da uniformização da compra e venda internacional: da lex mercatoria à Convenção de Viena de 1980. In: FRADERA, V. J.; MOSER, L. G. M. (Org.). Compra e Venda Internacional de Mercadorias - Estudos sobre a Convenção de Viena de 1980. São Paulo: Atlas, 2011, cap. 1, p. 1-21.

GAMA E SOUZA JR., Lauro da. Contratos Internacionais à luz dos Princípios do UNIDROIT 2004: soft law, Arbitragem e Jurisdição. Rio de Janeiro-São Paulo-Recife: Renovar, 2006.

GLITZ, Frederico Eduardo Zenedin. Apontamentos sobre o conceito de Lex Mercatoria. Revista Jurídica, v. 1, n. 28, p. 123-144, 2012. Disponível em: http://revista.unicuritiba.edu.br/index.php/RevJur/article/view/413/318. Acesso em: 5 jun. 2020.

GLITZ, Frederico Eduardo Zenedin. La Globalización del Derecho Contractual. Tradução Maria Noel Antas. São Paulo: Clássica, 2012. Disponível em: https://papers.ssrn.com/sol3/papers.cfm?abstract_id=2620384. Acesso em: 5 jun. 2020.

HABERMAS, Jürgen. Direito e Democracia: entre facticidade e validade. Tradução Flávio Beno Siebeneichler. Rio de Janeiro: Tempo Brasileiro, v.1, 1997.

LOPES, Christian Sahb Batista. A mitigação dos prejuízos no direito contratual. Belo Horizonte: UFMG, 2011. Apresentada como dissertação de doutorado, Faculdade de Direito da Universidade Federal de Minas Gerais, 2011. Disponível em:

https://repositorio.ufmg.br/handle/1843/BUOS-8MQG8H. Acesso em: 3 jun. 2020.

MARTINS-COSTA, Judith. A boa-fé no direito privado - sistema e tópica no processo obrigacional. 1. ed. São Paulo: Revista dos Tribunais, 2000.

MARTINS-COSTA, Judith. Os princípios informadores do contrato de compra e venda internacional na Convenção de Viena de 1980. Revista de Informação Legislativa, n. 126, Brasília, abr.-jun., 1995. Disponível em: http://www2. senado.leg.br/bdsf/bitstream/handle/id/176328/000497455.pdf?sequence=1. Acesso em: 5 jun. 2020.

MENEZES CORDEIRO, António Manuel da Rocha e, Da Boa-fé no Direito Civil. 4ª Reimpr. Coimbra: Almedina, 2011.

MORAIS, Ricardo Manoel Oliveira; SILVA, Adriana Campos. O liberalismo econômico e as práticas de segurança: o "avesso" das democracias liberais. Revista da Faculdade de Direito UFPR, Curitiba, PR, Brasil, v. 62, n. 3, p. 221 242, set./dez. 2017. ISSN 2236-7284. Disponível em: http://revistas.ufpr.br/direito/article/view/53720. Acesso em: 5 jun. 2020. DOI: http://dx.doi.org/10.5380/rfdufpr.v62i3.53720.

ONU. Assembleia Geral das Nações Unidas. Declaração Universal dos Direitos Humanos. 1948. Disponível em: https://nacoesunidas.org/wp-content/uploads/2018/10/DUDH.pdf. Acesso em: 07 jun. 2020.

PIGNATTA, Francisco Augusto. Controvérsias em torno do campo de aplicação da Convenção de Viena de 1980: o caso da teoria da culpa in contrahendo. In: FRADERA, V. J.; MOSER, L. G. M. (Org.). Compra e Venda Internacional de Mercadorias - Estudos sobre a Convenção de Viena de 1980. São Paulo: Atlas, 2011, cap. 2, p. 22-43. 
PIKETTY, Thomas. O Capital no século XXI. Tradução Mônica Baumgarten de Bolle. Rio de Janeiro: Intrínseca, 2014.

SOUSA SANTOS, Boaventura de. Por uma concepção multicultural de direitos humanos. Revista Crítica de Ciências Sociais, n. 48, p.11-32, 1997. Disponível em: http://www.boaventuradesousasantos.pt/media/pdfs/Concepcao_multicultural_direitos_humanos_RCCS48.PDF. Acesso em: 5 jun. 2020.

TIMM, Luciano Benetti. Common Law e Contract Law: uma Introdução ao Direito Contratual Norte-Americano. Revista do Instituto do Direito Brasileiro, v. 1, n. 1, p. 525-572, 2012. Disponível em: https://blook.pt/publications/ publication/54931b2e51e8/. Acesso em: 5 jun. 2020.

TOMUSHAT, Christian. International law: ensuring the survival of mankind on the eve a new century. General course on public international law. Recuil des cours, v. 281, p. 9-438, 1999.

UNIDROIT. Unidroit Principles of International Commercial Contracts. 2016. Disponível em: https://www.unidroit. org/english/principles/contracts/principles2016/principles2016-e.pdf. Acesso em: 07 jun. 2020.

Recebido/Received: 25.04.2019.

Aprovado/Approved: 04.07.2020. 